\title{
Group bargaining in supply chains
}

\section{Derek J. Clark ${ }^{1}$ (D) Jean-Christophe Pereau ${ }^{2}$}

Received: 19 April 2020 / Accepted: 15 January 2021 / Published online: 10 February 2021

(C) The Author(s) 2021

\begin{abstract}
We consider a vertical supply chain in which a monopoly retailer produces a good by assembling a number of essential components each of which is owned by a monopoly. Rather than making the common assumption that the component price is set in the same way for each owner, we investigate the possibility that the retailer may profit by bargaining with some owners in a group, whilst others set their component price to maximize own profit. Furthermore, component owners can self-select into one of these groups, and the retailer can affect group formation by adjusting the order of negotiations. We present conditions under which the retailer can encourage the formation of a bargaining group, and thereby improve its own and industry profit.
\end{abstract}

Keywords Complementary inputs · Bargaining $\cdot$ Supply chain

\section{JEL Classification C78}

\section{Introduction}

Modern production often involves assembly of many components, and a successful supply chain is dependent upon agreement between many actors. ${ }^{1}$ Negotiations in the chain may be difficult since they embody both the aspect of creating value in the chain, and distributing value between its members (Lax and Sebenius 1992). In an experimental analysis of bargaining in competing supply chains, Leider and Lovejoy (2016) note that the benefit of creating value through cooperation will not necessarily be realized due to the private profitability interests of each participant. Furthermore, they claim that managing the tension between integrative and distributive bargaining is

\footnotetext{
${ }^{1}$ Laussel (2008) documents that Airbus Industries has 600 subcontractors that provide equipment for aeroplane manufacture.
}

$凶 \quad$ Derek J. Clark derek.clark@uit.no

1 UiT - The Arctic University of Norway, Troms $\varnothing$, Norway

2 GREThA UMR CNRS 5113, University of Bordeaux, Bordeaux, France 
central to supply chain management research. In this paper we analyze a simple vertical market in which a manufacturer or retailer must assemble complementary components in order to satisfy product demand. In the status quo situation, all component owners set their component price independently to maximize own profit, and hence claim as much value as possible for themselves. We show that a simple cooperative group bargaining process over the component prices can increase the amount of profits to be distributed in the industry; when component owners have heterogeneous bargaining power, however, some prefer to not bargain in the group but to maximize individual profit. The retailer then attempts to move the situation away from the status quo by designing the negotiation context. Specifically, the retailer does not have the power to command that all component owners negotiate as part of the group, but he can design the timing of the negotiations by stipulating that those who bargain as a group can set their component prices before, after or at the same time as those who set component price to maximize own profit. We present conditions under which the retailer can announce an order of negotiation that leads to the formation of a unique bargaining group, which in turn leads to greater profit for the retailer than the status quo of independent profit maximization. The formation of a group that negotiates together is documented in practice by Nagarajan and Bassok (2008) who give several examples in which a selling alliance arises in supply chains, with some actors bundling their components and selling a kit to the retailer; this is reported to occur in aeroplane manufacture, agribusiness and in the semiconductor industry among others. ${ }^{2}$

The setting of intermediate prices in a supply chain has been modeled in many ways. Some authors consider our status quo situation in which the owners choose their component price to maximize own profit, given the expected price set by retailers for the final product (see for example Choi 1991). Others consider that bargaining between chain members will determine an intermediate price (Horn and Wolinsky 1988; von Ungern-Sternberg 1996; Dobson and Waterson 1997, were early examples of this). In many cases, the bargaining is modeled as the bilateral maximization of the Nash product, modified for bargaining power (for example Laussel 2008; Nagarajan and Bassok 2008; Spulber 2016, 2017; Draganska et al. 2010 and Sheu and Gao 2014). ${ }^{3}$ A common assumption in supply chain analysis is that all actors determine their price in the same manner, i.e. all actors strike a bilateral bargain with the downstream firm, or all set a linear price or two-part tariff to maximize own profit. We relax this assumption in our analysis, allowing some component owners to bargain, and others to set price to maximize own profit.

In bargaining models, a common assumption is that each supplier has identical bargaining strength (see, for example, Laussel 2008; Spulber 2017 and Nagarajan and Bassok 2008). This is unlikely to be the case, and is an assumption that we relax in our analysis. ${ }^{4}$ Bargaining strength may follow from the skill of the negotiator, may be related to the characteristics of the component, or arise from strategic considerations

\footnotetext{
2 See Nagarajan and Bassok (2008; p. 1483).

3 Clark and Pereau (2009) consider bargaining with alternating offers as in Rubinstein (1982).

${ }^{4}$ Spulber (2017) notes that in 2015 US companies had 72,000 purchasing managers and over 400,000 buyers who evaluate suppliers and negotiate supply contracts. It seems unlikely that they would be identical. Elfenbein et al. (2008) present evidence of experiments in an integrative bargaining environment suggesting that differences in individual skill affects the bargaining outcome.
} 
involving partial commitment (Muthoo 1996). An extensive review of the sources and consequences of asymmetric bargaining power can be found in Winkler (2006). In our model, the heterogeneity of bargaining strength plays a crucial role since those with the most power can gain a large profit from joining the bargaining group, while component owners with little bargaining power prefer to set intermediate price to maximize own profit. A configuration of component owners in and outside of the bargaining group has to exhibit stability in equilibrium, in the sense that no member wants to leave the group, and no outsider wishes to join (D'Aspremont et al. 1983). We consider open membership in which no component owner can refuse others the right to join the bargaining group (see Belleflamme 2000; Yi 1997, for a survey).

The paper closest to ours is Nagarajan and Bassok (2008) who analyze a supply chain with complementary components in which identical suppliers bargain bilaterally in sequence over division of a fixed pie with a retailer, and who can form coalitions in order to increase collective bargaining power in the process; they can furthermore use resources to influence their place in the bargaining order. In our model, the component prices affect the cost of the retailer and hence the product price which alters demand; hence, component owners must take account of this effect when setting the price of their component. Our framework allows some component owners to bargain over its own intermediate price collectively in a group with others, whilst some components are outside of the arrangement with the component price being set to maximize the profit of an individual owner. ${ }^{5}$ The bargaining that takes place in our model involves maximization of the joint product of the participants' profit, rather than bilaterally in sequence. ${ }^{6}$ In determining the composition of the components in the bargaining group endogenously, our work is also related to that of coalition formation. The literature distinguishes between coalitions in collusive markets (Stigler 1950) in which coalition formation induces a positive externality on the firms outside of the cartel by restricting production and increasing prices; coalitions in cost-reducing markets on the other hand induce a negative externality on non-members since the competitive position of the cartel is strengthened (Bloch 2002; Belleflamme 2000). Often simplifying assumptions will have to be made when considering endogenous coalition formation. As Brenner $(2009 ; 386)$ puts it: "The design of optimal coalition formation rules is a neglected issue in economic theory, in part because the analytical complexities which may arise when considering optimal endogenous coalition formation". Brenner (2009) considers a symmetric game in which only a single coalition forms in order to secure an analytically tractable model. We also consider the case in which a single coalition can form. ${ }^{7}$ Asymmetry in coalition formation is examined by Belleflamme (2000) who considers firms that can form cost-reducing cartels prior to competition. The asymmetry has two dimensions, one relating to the firm itself and one relating to the association to which the firm is attached, i.e. that the cost reduction may be relationship-specific. He restricts the number of coalitions that can form to at most two. When firms are symmetric, the

\footnotetext{
5 This split system is also considered by Leveque and Meniere (2011) in the context of patents in which some patent holders form a pool, whilst others remain outside as independent licensors.

${ }^{6}$ Given the large number of components that are involved in some supply chains, it is not unlikely that some negotiations will take place simultaneously.

${ }^{7}$ See Bloch (2002) for a model of sequential coalition formation in collusive and cost-reducing markets, in which several coalitions may form.
} 
unique equilibrium involves the formation of the grand coalition, whereas when firms are asymmetric there may be no equilibrium coalition, or several coalitions may form. Nagarajan and Bassok (2008) also allow for the possibility that several coalitions may form in their model with symmetric suppliers who all participate in bargaining. Since we allow for asymmetric suppliers and a mixed system of price setting, we restrict the number of coalitions that may form to one in order to get tractable results.

In our model, the retailer can effect the formation of the bargaining group by announcing the order in which he will negotiate with those who bargain and those who set component price independently. If component owners who set price independently get to do this first, then no bargaining group will form. Those who negotiate first take too large a share of the profits from the market to make cooperation worthwhile. Simultaneous negotiation with independent component owners and the bargaining group gives the same result when there are at least three component owners. Hence the retailer cannot move the market solution away from the status quo in which all owners maximize their own profit. In the special case of two components, the owners can form a bargaining group if they have sufficiently high and sufficiently close bargaining power; in this case, the possibility exists that the retailer can then achieve the fully cooperative solution, increasing profit for all participants over the status quo. We show that allowing the bargaining group to negotiate component price before the independent owners can lead to the formation of a stable bargaining group. However, without more structure on the group formation problem, the group of owners that bargain will not be unique. We recover uniqueness by assuming that component owners enter the bargaining group sequentially in the order of their bargaining power, and demonstrate the existence of a stable bargaining group that improves the profit of the retailer compared to the status quo.

Several strands of literature on one-to-many negotiation are related to our work. Some authors consider the effect of merger and concentration in the vertical supply chain (e.g. Gaudin 2018; Iozzi and Valletti 2014; Bergh et al. 2020). Bundling complementary components, or the formation of patent pools are examples of these types of analysis (see for example Flores-Fillol and Moner-Colonques 2011; Reisinger and Tarantino 2019). Patent pools function differently to the model that we present since patent owners negotiate collectively, and then divide up profits according to a pre-specified rule; in our model, component owners bargain together but receive an individual share of the profit decided by their bargaining power.

The sequencing of negotiations is also relevant to our work. Münster and Reisinger (2018) investigate a model in which a principal bargains bilaterally with two agents who have different bargaining power. The principal chooses which agent to bargain with first, focusing on the case in which no renegotiation is possible. They show that welfare is maximized when the stronger agent bargains first, and this also maximizes the return of the principal if there is a negative externality between the agents in the bargaining situation (retailers who sell substitute products for example). This analysis adapts Möller (2007) who assumes that the principal has all of the bargaining power and can choose between simultaneous and sequential offers; if the externalities between agents become weaker the more an agent trades, then simultaneous bargaining is preferred by the principal. Sequential negotiations can be beneficial for the principal if the amount of trading increases the externality between agents since this lowers the 
outside option of those who contract later in the sequence. Xiao (2018) endogenizes the sequence of bargaining in a model with a buyer who negotiates with several sellers of complementary goods, showing that he prefers to negotiate with small sellers (low valuation) first. Krasteva and Yildirim (2012) consider two sellers of complementary goods who do not know the buyer's the stand-alone value of their products. Indeed, the buyer must choose the sequence of negotiations before privately learning these standalone values, and each negotiation is modeled as a random-proposer one-shot bargain. The bargaining power of the seller relative to the buyer is given by the probability of the seller making the offer. When bargaining in sequence, if the buyer proposes, he offers to pay the second seller his marginal cost. If sellers have diverse bargaining power and the weak seller negotiates last, then the stronger seller will act aggressively if allowed to bargain first; the buyer prefers to counteract this and begin with the weaker seller. When both sellers have high bargaining power, the buyer prefers to negotiate with the stronger one first; should the buyer agree with the stronger seller first, it is more likely that he will be able to agree with the weaker seller at the second stage, gaining the payoff from combining the complementary goods. Krasteva and Yildirim (2019) extend this framework to allow the buyer to acquire information on the stand-alone values before announcing the sequence of negotiation.

The paper is organized as follows. The basic model is set up in Sect. 2, where we solve for two benchmark cases: one in which all component owners set their intermediate price to maximize own profit, and one in which all component owners bargain with the retailer, setting component price cooperatively by maximizing the Nash product. Section 3 investigates the situation that arises when some component owners bargain over their component price while others set it independently to maximize own profit. These results are used in Sect. 4 to examine conditions under which the retailer can design the order of negotiations in order to influence the formation of a stable bargaining group, with the aim of increasing his own profit from the sale of the final product. Section 5 concludes. Proofs are collected in the "Appendix".

\section{The model}

There are $i=1, \ldots, n$ component owners who each own the exclusive right to that component. As in the Cournot model of complementary monopolies, these firms supply their component to a single downstream retailer who in turn must assemble one unit of each component part to make a single unit of the final product for which demand is given by

$$
D(p)=1-p
$$

where $p$ is the product price. The retailer is the only seller of this product, and pays a component price to owner $i$ at a rate of $w_{i}$ per unit; due to the technology, the number of units sold of the component is equal to the number of units sold of the final product. For simplicity we assume that the retailer incurs no other production cost. Hence the profits of each component owner, and the retailer $R$ are given by

$$
\pi_{i}=w_{i}(1-p)
$$




$$
\pi_{R}=\left(p-\sum_{i=1}^{n} w_{i}\right)(1-p) .
$$

The retailer sets a product price to maximize his profit given the component prices $w_{i}$ :

$$
\frac{\partial \pi_{R}}{\partial p}=0 \Leftrightarrow p=\frac{1+\sum_{j=1}^{n} w_{j}}{2} .
$$

Inserting (4) into (2) and (3) gives the profit function of monopoly $i$, the retailer and the industry $(\pi)$ as

$$
\begin{aligned}
\pi_{i} & =\frac{1}{2} w_{i}\left(1-\sum_{j=1}^{n} w_{j}\right) \\
\pi_{R} & =\frac{1}{4}\left(1-\sum_{j=1}^{n} w_{j}\right)^{2} \\
\pi & =\pi_{R}+\sum_{i=1}^{n} \pi_{i}=\frac{\left(1-\sum_{j=1}^{n} w_{j}\right)\left(1+\sum_{j=1}^{n} w_{j}\right)}{4} .
\end{aligned}
$$

Note that retailer and industry profit is dependent only on the sum of the component prices. We now investigate two benchmark solutions, one in which the actors do not cooperate, and one in which they cooperate by striking a Nash bargain.

Lemma 1 indicates the market solution assuming that each monopoly component owner sets its price independently to maximize its own profit; here we indicate the equilibrium value by an $I$ superscript.

Lemma 1 When each monopoly component owners sets intermediate price to maximize own profits, the equilibrium is characterized by

$$
\begin{aligned}
w^{I} & =\frac{1}{1+n}, \\
\pi_{i}^{I} & =\frac{1}{2(1+n)^{2}}, \\
\pi_{R}^{I} & =\frac{1}{4(1+n)^{2}}, \\
\pi^{I} & =n \pi_{i}^{I}+\pi_{R}^{I}=\frac{1+2 n}{4(1+n)^{2}}, \\
p^{I} & =\frac{1+2 n}{2(1+n)} .
\end{aligned}
$$

Since each component is essential for production, and the technology requires one unit of each, the intermediate price set is identical for each component, and decreasing in the number of components. 
Suppose that the component owners and the retailer seek a cooperative solution, determining the intermediate prices by bargaining. Specifically, assume that the actors maximize a Nash program with bargaining power of the retailer denoted $r$ and that of owner $i$ by $m_{i}$, collected in vector $\mathbf{m}$. Let $M=\sum_{j=1}^{n} m_{j}$, and $W=\sum_{k=1}^{n} w_{k}{ }^{8}$ Using (5) and (6), the Nash program-denoted by $\Omega$ and given that all component owners bargain over their price-is

$$
\max _{w_{i}} \Omega(r, \mathbf{m})=\left(\frac{1}{4}\right)^{r}\left(\frac{1}{2}\right)^{M}(1-W)^{2 r+M} \prod_{j=1}^{n}\left(w_{j}\right)^{m_{j}} .
$$

Lemma 2 gives the equilibrium values in the cooperative bargaining solution, denoted by $C$ :

Lemma 2 Maximizing the Nash program yields the following equilibrium values

$$
\begin{aligned}
w_{i}^{C}(r, \mathbf{m}) & =\frac{m_{i}}{2(r+M)} \\
\pi_{i}^{C}(r, \mathbf{m}) & =\frac{1}{8} \frac{m_{i}(2 r+M)}{(r+M)^{2}} \\
\pi_{R}^{C}(r, \mathbf{m}) & =\frac{1}{16} \frac{(2 r+M)^{2}}{(r+M)^{2}} \\
\pi^{C}(r, \mathbf{m}) & =\sum_{j=1}^{n} \pi_{j}^{C}(r, \mathbf{m})+\pi_{R}^{C}(r, \mathbf{m})=\frac{1}{16} \frac{(2 r+3 M)(2 r+M)}{(r+M)^{2}} \\
p^{C}(r, \mathbf{m}) & =\frac{2 r+3 M}{4(r+M)} .
\end{aligned}
$$

Recalling the definition of $M$, especially that it depends on $m_{i}$, one can calculate that $\frac{\partial w_{i}^{C}}{\partial m_{i}}>0$ so that owners with the largest bargaining power achieve the highest component price as expected. The product price is increasing in $m_{i}$ and decreasing in $r$. The stronger the owners are in the negotiations, the higher the component price which pushes up the final product price, lowering consumer welfare in the product market.

It is straightforward to verify the following result, where the full expression for $m_{i}^{+}\left(n, r, M_{-i}\right)$ is given in the "Appendix":"

Proposition 1 With full participation in the bargaining group, $\pi^{C}(r, \mathbf{m})>\pi^{I}$ and $\pi_{R}^{C}(r, \mathbf{m})>\pi_{R}^{I}$. Owners with sufficiently low bargaining power prefer $I$ :

$$
\pi_{i}^{I}>\pi_{i}^{C}(r, \mathbf{m}) \Leftrightarrow m_{i}^{+}\left(n, r, M_{-i}\right)>m_{i}
$$

\footnotetext{
8 In all cases, the disagreement payoff is set to zero. This corresponds to Laussel (2008), reflecting the fact that all component owners must agree for the final good to be produced.

${ }^{9}$ Where $M_{-i}=M-m_{i}$.
} 
The bargaining solution increases industry and retailer profit compared to a situation with non-cooperative price setting by the component holding monopolies. For a given distribution of the $\mathbf{m}$, it is clear that an owner with a larger bargaining power gains a larger profit than his rivals. Hence, some owners may prefer the bargaining solution whilst others gain most profit from the non-cooperative framework. This suggests that one should seek to determine which component owners will be in a (stable) bargaining group, and which stay outside. We turn to this issue now.

\section{Partial bargaining}

Component owners with sufficiently low bargaining power would prefer to set their intermediate price non-cooperatively to maximize own profit, whereas those with high bargaining power prefer the cooperative framework. Here we explore the possibility that one group bargains with the retailer over their component price, while others fix their payment non-cooperatively outside of this agreement. Let $B$ represent the set of owners that bargain with the retailer, and $N$ the set that does not; assume that there are $\beta \geq 1$ members in $B$ and $n-\beta$ in $N$. Component prices are determined groupwise in sequence. In case $N B$, the non-bargaining group sets its component prices first with each owner maximizing his own profit; these component prices are revealed and the members of the bargaining group set their prices by maximizing the Nash product with the retailer. The order of negotiation is reversed in case $B N$ where members of the bargaining group set component prices to maximize the Nash product without knowing the choice of those who are outside of this group; then the outside owners observe the intermediate prices set, and choose their own component price to maximize own profit. In case $S I M$, both groups set their component price simultaneously, without knowing the choice of the other group.

Fix a membership for each group; for those who bargain, it is both the number of members and their bargaining strengths that are important and let the sum of bargaining power for this group be $\mu=\sum_{i} m_{i}$ for $i \in B$. The next lemma gives the profits achieved by the component owners that are part of the bargaining group and those who are not, depending on the order of play in the cases outlined above. For completeness, expressions for intermediate prices, final product price and the profit of the retailer are given in the "Appendix".

Lemma 3 Fix a membership for each group $B$ and $N$. The realized profits for component owners in each group and the retailer are given by

$$
\begin{aligned}
\pi_{i}^{N B} & =\frac{1}{8} \frac{m_{i}(2 r+\mu)}{(r+\mu)^{2}(1+n-\beta)^{2}}, i \in B \\
\pi_{j}^{N B} & =\frac{1}{4} \frac{2 r+\mu}{(r+\mu)(1+n-\beta)^{2}}, j \in N \\
\pi_{i}^{B N} & =\frac{1}{8} m_{i} \frac{2 r+\mu}{(r+\mu)^{2}(1+n-\beta)}, i \in B
\end{aligned}
$$




$$
\begin{aligned}
\pi_{j}^{B N} & =\frac{1}{8}\left(\frac{2 r+\mu}{(r+\mu)(1+n-\beta)}\right)^{2}, j \in N \\
\pi_{R}^{N B} & =\pi_{R}^{B N}=\frac{1}{16}\left(\frac{2 r+\mu}{(r+\mu)(1+n-\beta)}\right)^{2} \\
\pi_{i}^{S I M} & =\frac{1}{2} m_{i} \frac{2 r+\mu}{(2(r+\mu)+(n-\beta)(2 r+\mu))^{2}}, i \in B \\
\pi_{j}^{S I M} & =\frac{1}{2}\left(\frac{2 r+\mu}{2(r+\mu)+(n-\beta)(2 r+\mu)}\right)^{2}, j \in N \\
\pi_{R}^{S I M} & =\frac{1}{4}\left(\frac{2 r+\mu}{2(r+\mu)+(n-\beta)(2 r+\mu)}\right)^{2} .
\end{aligned}
$$

Industry profits are

$$
\begin{aligned}
\pi^{N B} & =\pi^{B N}=\frac{1}{16} \frac{(2 r+\mu)(2 r+3 \mu+4(n-\beta)(r+\mu))}{(r+\mu)^{2}(1+n-\beta)^{2}} \\
\pi^{S I M} & =\frac{1}{4} \frac{(2 r+\mu)(2 r+3 \mu+2(n-\beta)(2 r+\mu))}{(2(r+\mu)+(n-\beta)(2 r+\mu))^{2}} .
\end{aligned}
$$

Note that industry and retailer profit is the same in each of the sequential frameworks due to the fact that these magnitudes are only dependent on the sum of component prices (see (7)); the "Appendix" shows that this sum is identical in case $N B$ and $B N$.

In order to be able to compare the different frameworks, we must assume the same distribution of component owners and bargaining powers, i.e. that $n>\beta \geq 1$ and $\mu$ is the same in each case $N B, B N$ and $S I M .{ }^{10}$ Comparison of the profit expressions is straightforward:

Proposition 2 Fix a membership of $N$ and $B$ with $n>\beta \geq 1$. Then

$$
\begin{aligned}
& \pi^{S I M}>\pi^{N B}=\pi^{B N} ; \pi_{R}^{C}(r, \mathbf{m})>\pi_{R}^{S I M}>\pi_{R}^{N B}=\pi_{R}^{B N} \\
& \pi^{S I M}>\pi^{I} ; \quad \pi_{R}^{S I M}>\pi_{R}^{I} \\
& \pi^{N B}=\pi^{B N}>(<) \pi^{I} \text { and } \pi_{R}^{N B}=\pi_{R}^{B N}>(<) \pi_{R}^{I} \text { for and } \\
& \quad \quad r>(<) \frac{\mu(1+n-2 \beta)}{2 \beta} \\
& \pi_{i}^{B N}>\pi_{i}^{S I M}>\pi_{i}^{N B}, i \in B \\
& \pi_{j}^{N B}>\pi_{j}^{B N}, j \in N \\
& \pi_{j}^{N B}>\pi_{j}^{S I M} \text { for } n-\beta=1, j \in N \\
& \pi_{j}^{N B}<\pi_{j}^{S I M} \text { for } n-\beta \geq 2, j \in N .
\end{aligned}
$$

For the component owners who are in the bargaining group, there is a first-mover advantage, and they prefer to set intermediate price before the outsiders. The worst

\footnotetext{
10 These variables will be determined endogenously in the next section. When $\beta=n$, then soultion $C$ (full bargaining) obtains, and when $\beta=0$ the independent solution ( $I$ ) occurs.
} 
outcome for the bargaining group is achieved when they set component price after the profit-maximizing outsiders; profits from the simultaneous framework lie in between the two sequential ones. The component owners who are outside of the bargaining group prefer to set their component price first rather than second. Unless there is a single member of $N$, most profit is obtained from the simultaneous framework. First best for a component owner who is the only one to set price independently, is to set price first, and then let the other actors bargain over the division of what is left. However, if two or more owners want to set price independently, they earn from the simultaneous setup where each group moderates its claim due to the uncertainty of what the other group will do. This gives the largest pie to be shared out in terms of total profit as can be seen from Proposition 2, and is also the preferred framework of the retailer. Of course, the simultaneous framework with $\beta=n$ is identical the the pure bargaining solution $(C)$.

Note that the profit comparisons of the industry as a whole and the retailer are perfectly aligned, and that the profits accruing from both sequential frameworks are the same for retailer (and at the industry level) since they give the same sum of component prices. Whether the retailer would prefer a sequential framework to the one in which component owners set price independently is parameter specific, usually dependent on a large enough bargaining power of the retailer compared to the bargaining group. In one specific case, however, the distribution of bargaining powers does not play a part: ${ }^{11}$

Corollary 1 When $\beta>\frac{1+n}{2}$, then $\pi^{N B}=\pi^{B N}>\pi^{I}$ and $\pi_{R}^{N B}=\pi_{R}^{B N}>\pi_{R}^{I}$ independent of bargaining power.

Industry and retailer profit are larger in the sequential framework compared to the independent when over half the component owners bargain, whatever the distribution of the bargaining powers. ${ }^{12}$

\section{Designing market structure}

The retailer achieves different profit outcomes depending on the structure that is put in place, with his best solution being the one in which all component owners bargain simultaneously over intermediate prices (case $C$ - see Propositions 1 and 2). Suppose initially that the intermediate prices are set by the owners independently, so that case $I$ is the status quo. How might the retailer set about achieving a solution that improves his own profit? In the absence of the power to dictate that the full bargaining solution will be chosen, we consider other options available to the retailer in designing this market. Suppose that the retailer can only choose a regime $N B, B N$, or $S I M$ before the intermediate prices are set, and does not have the power to dictate to which group, $N$ or $B$, a component owner will belong. Having announced a regime, the component owners

11 In the condition $r>\frac{\mu(1+n-2 \beta)}{2 \beta}$, the right-side is negative-and hence the inequality is always fulfilled-under the condition in the Corollary.

12 Suppose that $r=1$; then rearranging the condition in (28) gives $\beta>\frac{\mu(1+n)}{2(1+\mu)}$, where the right-handside reaches $\frac{1+n}{2}$ in the limit as $\mu$ grows. Hence, the condition is fulfilled independent of bargaining power whenever at least half of the owners are in the bargaining group for this case. 
choose membership of the bargaining or non-bargaining group, and then prices are determined. Hence, the component owners find their way into an agreement in which some of them bargain over the component price, whilst others set it independently to maximize own profit. To narrow down the set of possible agreements, and final outcomes, we now determine under which conditions such an agreement can be stable. We require both internal and external stability in the sense of D'Aspremont et al. (1983) in the presence of heterogenous players that differ in their bargaining power. Consider a situation in which there are $n-\beta$ members of group $N$ and $\beta$ in group $B$ characterized by the vector of bargaining power $\tilde{\mathbf{m}}$. For internal stability, it cannot be the case that any of the members in $B$ can join group $N$ and increase its own profit:

$$
\pi_{i \in B}(\beta, \widetilde{\mathbf{m}}) \geq \pi_{i \in N}\left(\beta-1, \tilde{\mathbf{m}}_{-i}\right)
$$

where $\widetilde{\mathbf{m}}_{-i}$ is the vector of bargaining powers of those in $B$ apart from $i$. At the same time, external stability demands that it cannot be profitable for a member of group $N$ to join the group of bargainers:

$$
\pi_{j \in N}(\beta, \widetilde{\mathbf{m}}) \geq \pi_{j \in B}\left(\beta+1, \widetilde{\mathbf{m}}, m_{j}\right) .
$$

When (29) and (30) are both fulfilled, the bargaining group is stable.

The game thus proceeds as follows:

Stage 1. The retailer announces the order of negotiation from the set $\{N B, B N, S I M\}$. Stage 2. The component owners form groups $B$ and $N$.

Stage 3. Component prices are determined and production takes place.

The retailer attempts to design the market by announcing a negotiation framework, and the profit outcome will depend on how component owners select into group $B$ and $N$. Moving away from the status quo (case $I$ ) depends upon finding a stable coalition within the framework announced by the retailer. To examine the optimal choice of the retailer, we now proceed by ordering component owners according to their bargaining power, $m_{1}>m_{2}>\cdots>m_{n}$, and normalizing the bargaining power of the retailer to one: $r=1$. At stage 2 , situations may arise in which several groupings of component owners can be stable, i.e. there is not a unique bargaining group. Denote by $B=\{\varnothing\}$ the empty bargaining group, which hence represents the status quo solution. If $B=\{\varnothing\}$ is one of several stable bargaining groups, then we assume that the status quo of case $I$ persists. With this assumption, the next proposition shows that the retailer cannot move away from the status quo by announcing order of negotiation $N B$ or SIM.

Proposition $3(i)$. When the retailer announces negotiation order $N B$, then $B=\{\varnothing\}$ is the unique stable bargaining group. (ii). Suppose the retailer announces negotiation order SIM. I. For $n \geq 3$, then $B=\{\varnothing\}$ is the unique stable bargaining group. II. When $n=2, B=\{\varnothing\}$ is always a stable bargaining group, although it may not be unique.

The only stable solution when the bargaining group sets component price second, will be for all owners to set price independently to maximize own profit. This is shown in the "Appendix" to be internally stable, and is trivially externally stable since there 
are no owners left to break into the group $N$. Hence the realized profits for each component owner and the retailer are given by the independent profit-maximizing solution in (9) and (10). The final goods price is $p^{I}$ in (12).

Recall that simultaneous component price setting and bargaining is the framework that maximizes industry profit for a given distribution of component owners in the two groups; Proposition 3, however indicates that this is not a framework that the owners will converge to of their own free will. When there are more than two components, any coalition involving some of the owners in the bargaining group will be unstable. The component owner with the lowest bargaining power can always do better by moving to the group that sets price independently. The profit of this owner from bargaining is by (23) falling in the collective bargaining power of the other component owners in group $B$, so that the component with lowest power is most tempted to leave. In this case, the simultaneous framework yields a realized profit to the component owners from the independent solution $I$ in (9) and (10). When there are only two components, an outcome in which both component owners belong to $N$ is stable. It may, however, not be the unique outcome, and the "Appendix" shows that $B=\{1,2\}$ is stable if the bargaining power of each component owner is large in relation to that of the retailer (normalized to 1 ), and that $m_{2}$ is sufficiently close to $m_{1}$ in order for 2 to stay in the coalition. Given the assumption that a bargaining group does not form if $B=\{\varnothing\}$ is stable, announcing SIM as the order of negotiation will give the status quo solution.

The only candidate for achieving a profit level other than that associated with the status quo is then for the retailer to announce structure $B N$. As long as the owner with largest bargaining power has sufficient strength, the empty bargaining set is not stable, and it may be feasible to move away from status quo solution $I$.

Proposition 4 If $m_{1}>\frac{2}{n-1}$ then $B=\{\varnothing\}$ is not a stable bargaining group in framework $B N$.

When the component owner with the largest bargaining power is sufficiently influential, he will break out of the coalition with all owners in $N$, rendering it internally unstable. This means that the retailer, by announcing this order of negotiations, can move the solution away from the status quo, towards $B N$ which gives more profit if the condition in (28) is fulfilled. The highest level of profit for the retailer is case $C$ when all owners are in the bargaining set. To what extent it is possible to enforce this solution by announcing negotiation structure $B N$ is the subject of the next proposition.

Proposition 5 Suppose that the retailer announces order of negotiation $B N$. The grand coalition $B=\{1,2, \ldots, n\}$ is not stable for $n \geq 4$.

Although the grand coalition, and solution $C$, is not attainable with four or more component holders, we demonstrate below the existence of a bargaining set that is not complete but is profit-improving for the retailer. First, we turn attention to the special case of $n=2$ to demonstrate that partial bargaining may be feasible for the retailer to implement, but that this is not necessarily desirable. For this case, the proof of Proposition 4 shows that both component owners setting their prices independently is a stable solution for $2>m_{1}$. Owner 2 , with the lower bargaining power, has most to gain from leaving the grand bargaining coalition $B=\{1,2\}$; using (20) and (21), 2 


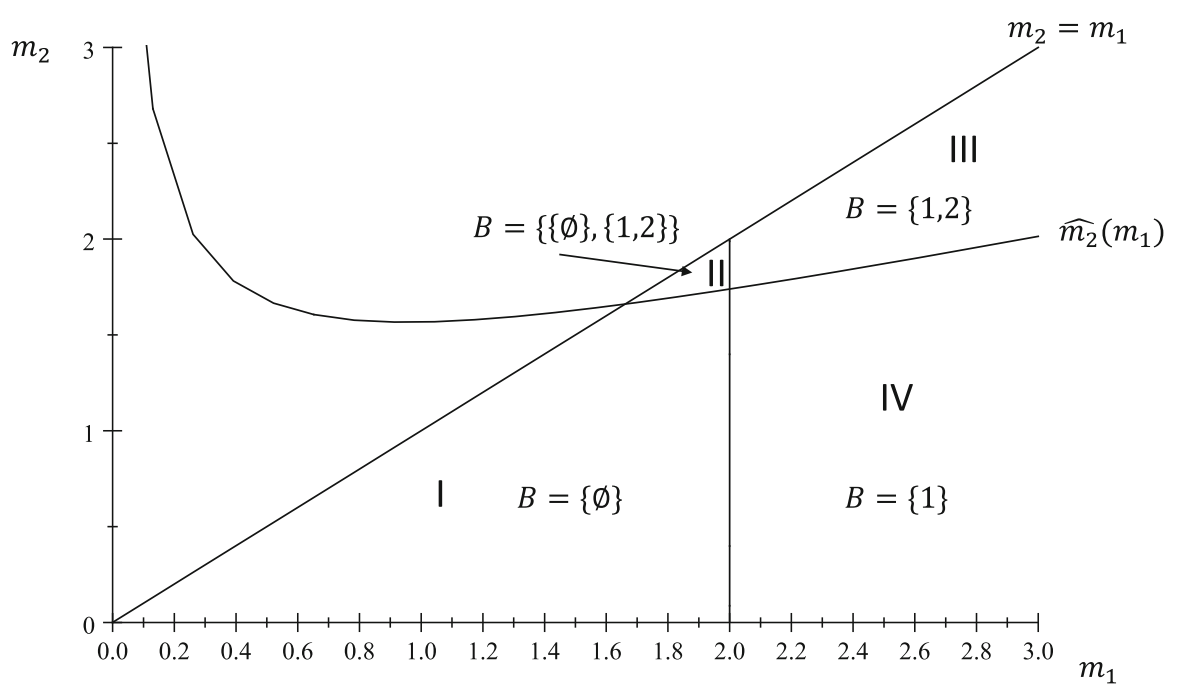

Fig. 1 Stable coalitions, case BN with $n=2$

will remain if

$$
\frac{1}{8} m_{2} \frac{2+m_{1}+m_{2}}{\left(1+m_{1}+m_{2}\right)^{2}}-\frac{1}{8} \frac{\left(2+m_{1}\right)^{2}}{4\left(1+m_{1}\right)^{2}}>0
$$

which can be solved to show that owner 2 stays in the grand coalition if $m_{2}>$ $\widehat{m}_{2}\left(m_{1}\right)=\left(m_{1}+2\right) \frac{2 \sqrt{m_{1}\left(m_{1}+1\right)^{3}}-m_{1}\left(1+m_{1}\right)}{m_{1}\left(3 m_{1}+4\right)}$. The situation is depicted in Fig. 1, where we are interested in the area below the 45-degree line since owner 1 has the larger bargaining power.

Notice first, that when $2>m_{1}$ and $\widehat{m}_{2}\left(m_{1}\right)>m_{2}$ (area I) the bargaining set is empty. However, even though $2>m_{1}$, this is not the only possible outcome for a stable coalition as there is a small area in which $2>m_{1}>m_{2}>\widehat{m}_{2}\left(m_{1}\right)$, so that both component owners bargaining and both setting price independently are stable coalitions (area II). When both set prices independently, 1 has the larger incentive to break out but does not in this area. When both bargain, 2 has the larger incentive to leave, but does not. When $m_{1}>2$, owner 1 prefers to bargain, being joined by 2 when $m_{2}>\widehat{m}_{2}\left(m_{1}\right)$ (area III), and remaining alone when not (IV). Since the status quo is stable in areas I and II of Fig. 1, the retailer does not gain from announcing $B N$ as the order of negotiations. In area III, both players bargaining in the grand coalition is the unique outcome, and solution $C$ obtains, improving the profit of the retailer beyond the status quo. Sustaining this is the "threat" that any player who breaks out of the agreement will have to set component price after those who remain in the bargaining group. In area IV, a partial bargaining solution is the unique outcome where owner 1 bargains his component price first, and then owner 2 chooses his profit-maximizing price. With $r=1, \mu=m_{1}, n=2$ and $\beta=1$, the condition in (28) guaranteeing that $\pi_{R}^{B N}>\pi_{R}^{I}$ is $2>m_{1}$, a contradiction. Hence for $n=2$, the retailer benefits from announcing order of negotiations $B N$ when the bargaining powers fall in area III of Fig. 1, but allowing the status quo to continue otherwise. 
When $n>2$ component holders, the formation of a unique bargaining group is not guaranteed and hence the retailer cannot be certain which combination of component owners will form if he announces $B N$ as the order of negotiation, and can therefore not know whether this is profit improving compared to the independent solution. As an example, suppose $n=3, m_{1}=2.5, m_{2}=2.3, m_{3}=1.75$; then the coalitions $B=\{1,2\}$ and $B=\{1,3\}$ are both internally and externally stable and give the retailer more profit than the independent solution. The retailer gets the most profit when the sum of the bargaining powers in the bargaining group is lowest, i.e. when $B=\{1,3\}$.

In order to achieve formation of a unique coalition, we can either change the stability requirements, or the manner in which the coalition forms. In the following analysis, we assume that the conditions for internal and external coalition stability remain unchanged, but that component owners consider entry into the coalition sequentially. Specifically, we assume sequential entry according to size of bargaining power, where component owner 1 first decides whether to enter group $B$ or not; having observed whether 1 enters the coalition, 2 decides whether or not to enter, followed in sequence by 3 and so on. Given this sequential entry, the proof of Proposition 4 states that a bargaining group will exist as long $m_{1}>\frac{2}{n-1}$ since this guarantees that owner 1 would rather bargain alone with the retailer than set component price independently. Given that owner 1 has entered the bargaining group, component owner 2 (with $m_{2}<m_{1}$ ) then compares the profit from joining the coalition with that of remaining outside of it. If he decides to join then the bargaining group consisting solely of owner 1 is not externally stable; furthermore, if 2 decides to join the bargaining group, 1 will not want to leave since the payoff from bargaining is increasing in bargaining power. This means that the coalition consisting of 1 and 2 is internally stable. Should owner 3 $\left(m_{3}<m_{2}\right)$ decide not to join 1 and 2 , then no players later in the sequence will wish to join either. Then $B=\{1,2\}$ is internally and externally stable. Hence, we can find a unique stable coalition by identifying a player $k=\{1,2, \ldots, n\}$ such that this player enters the bargaining group, but $k+1$ does not. The retailer can identify the stable bargaining group given $n$ component owners, and then compare its profit to the case of independent profit maximization.

Owner $k$ will enter the bargaining group along with owners $1, \ldots, k-1$ as long as

$$
\frac{1}{8} m_{k} \frac{2+\mu_{-k}+m_{k}}{\left(1+\mu_{-k}+m_{k}\right)^{2}(1+n-k)}>\frac{1}{8}\left(\frac{2+\mu_{-k}}{\left(1+\mu_{-k}\right)(1+n-(k-1))}\right)^{2}
$$

where $\mu_{-k}=\sum_{i=1}^{k-1} m_{i}$. This can further be reduced to $0<\Delta$, where

$$
\begin{aligned}
\Delta= & \left(\left(\mu_{-k}+1\right)^{2}(n-k)^{2}+\mu_{-k}\left(3 \mu_{-k}+4\right)(1+n-k)\right) m_{k}^{2} \\
& +\left(\mu_{-k}+2\right)\left(\mu_{-k}+1\right)\left((n-k)^{2}\left(\mu_{-k}+1\right)+2 \mu_{-k}(1+n-k)\right) m_{k} \\
& -\left(\mu_{-k}+2\right)^{2}\left(\mu_{-k}+1\right)^{2}(1+n-k)
\end{aligned}
$$

which is convex in $m_{k}$ with positive slope and negative value at $m_{k}=0$. Hence, $k$ joins the bargaining group as long as $m_{k}$ is larger than the positive root of $\Delta=0$. In the "Appendix" this is given in its closed form, but here we write the positive root as 


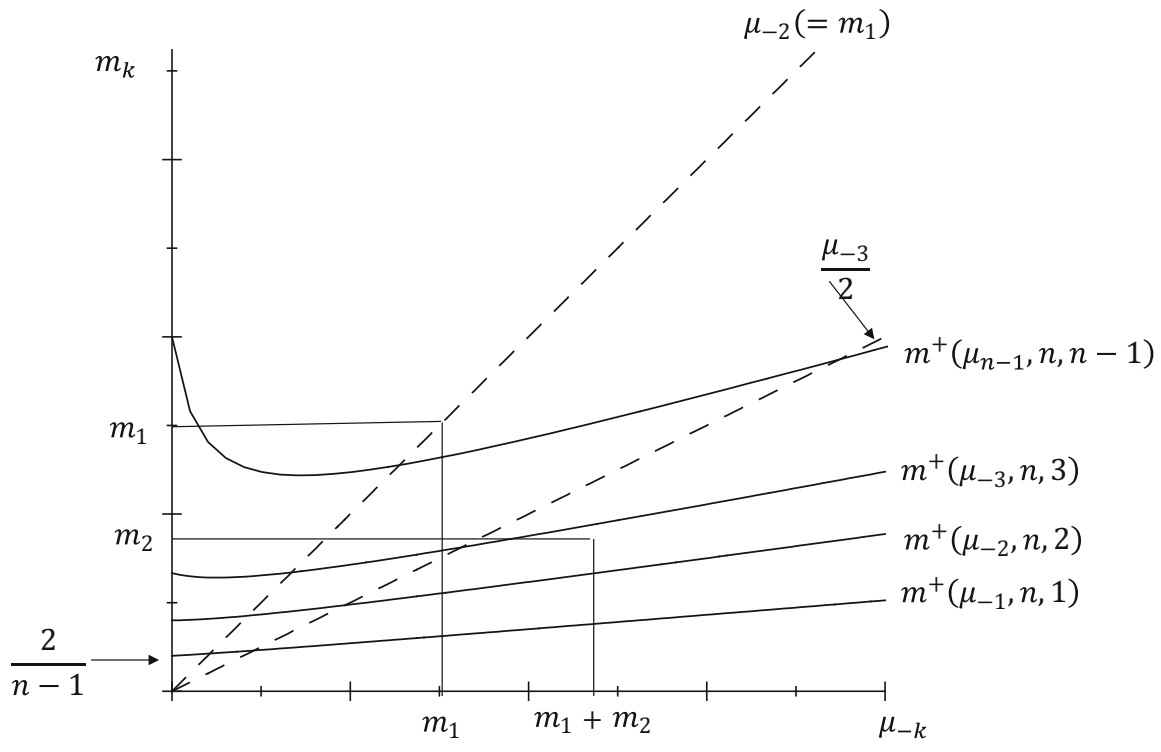

Fig. 2 Stable bargaining group in case BN with sequential entry

$m^{+}\left(\mu_{-k}, n, k\right)$. Each critical value for $m_{k}$ is associated with one of the level curves in Fig. 2. Owner 1 enters the bargaining group as long as $m_{1}>m^{+}(0, n, 1)=\frac{2}{n-1}$. Owner 2 then has to have an $m_{2}$ which is below $m_{-1}$ but above $m^{+}\left(\mu_{-2}=m_{1}, n, 2\right)$; this is clearly true in Fig. 2, so owner 2 enters the bargaining group. For entry of owner 3 requires $m_{2}>m_{3}>m^{+}\left(\mu_{-3}, n, 3\right)$, but this cannot occur as drawn in Fig. 2 for $\mu_{-3}=m_{1}+m_{2}$. Hence, the stable bargaining group here is $B=\{1,2\}$.

Figure 2 also demonstrates the monotonicity of the entry decision in the bargaining power, since the demand on this parameter is higher for each owner that enters. Also drawn in Fig. 2 is $m^{+}\left(\mu_{n-1}, n, n-1\right)$ which is the level that the owner with the lowest bargaining power $\left(m_{n}\right)$ must have to enter and make up the grand coalition of all component owners. The dashed lines drawn represent the average bargaining power of the bargaining group before owner $k$ makes his decision. Due to entry in sequence of falling bargaining power, it must be the case that $\frac{\mu_{-k}}{k-1}>m_{k}$. The proof of Proposition 5 shows that the curve $m^{+}\left(\mu_{n-1}, n, n-1\right)$ always lies above $\frac{\mu_{-n}}{n-1}$ for $n \geq 4$, ruling out the grand coalition in these cases.

As long as $m_{1}>\frac{2}{n-1}$, the retailer can announce $B N$ as the order of negotiations, and be sure that a unique stable bargaining group will form given sequential entry in order of rising bargaining power. However, this may not always be profitable compared to the solution in which all owners set their component prices independently. The retailer knows the number of component owners and their bargaining power and can hence calculate the bargaining group that will arise; he then needs to check whether (28) is fulfilled to be sure that announcing $B N$ will be a profitable strategy or not. As a demonstration, we suppose more structure on the bargaining powers by supposing that $m_{1}$ is largest and each successive power declines at a constant rate $\delta$ so $m_{k}=$ 


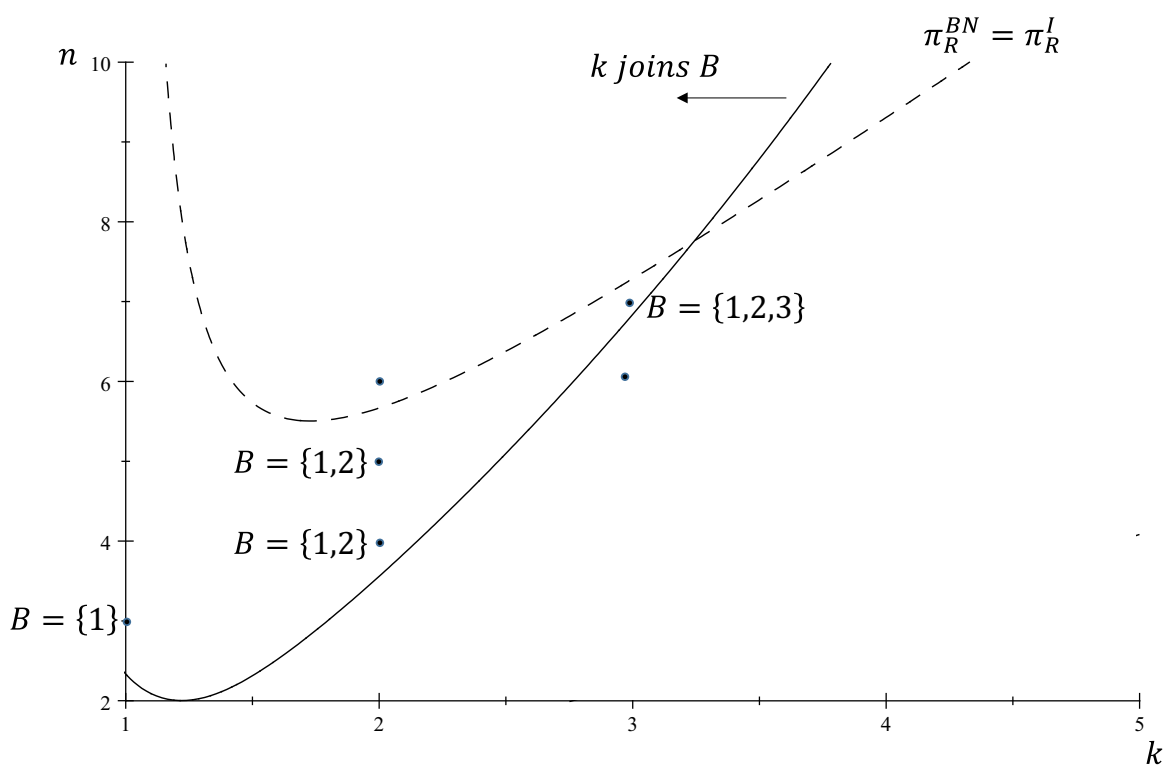

Fig. 3 Stable and profitable bargaining groups: a numerical example

$\delta^{k-1} m_{1}, \mu_{-k}=\sum_{j=1}^{k-1} m_{j}=m_{1} \sum_{j=1}^{k-1} \delta^{j-1}=m_{1} \frac{\left(1-\delta^{k-1}\right)}{(1-\delta)} .^{13}$ Then owner $k$ in the sequence enters the bargaining group as long as (31) is fulfilled; using (28), given that there are $k$ members of the bargaining group, this is profitable for the retailer if

$$
k>\frac{\mu_{k}(1+n)}{2\left(\mu_{k}+1\right)} .
$$

Figure 3 illustrates a numerical example in which $m_{1}=1.5$ and $\delta=0.75$. For each $n$, owner $k$ joins the bargaining group above and to the left of the whole line, and bargaining groups below the dashed line give the retailer more profit than the independent solution. When $n=2$, the bargaining set is empty (since $m_{1}=1.5<$ $\frac{2}{n-1}=2$ in this case). For $n=3$, owner 1 joins the bargaining group, but 2 does not; this is profitable for the retailer. When there are four, five or six owners, both 1 and 2 join the bargaining group; ${ }^{14}$ however, the retailer profits from this only if the number of owners is four or five. With seven owners, the stable bargaining group of $B=\{1,2,3\}$ forms, and gives more profit to the retailer than the independent solution. From $n \geq 8$, no stable bargaining groups are profitable for the retailer.

As $m_{1}$ falls, but with the same $\delta$, more combinations of bargaining groups are profitable for the retailer, but fewer bargaining groups form. For example if $m_{1}=1$, then $B=\{1,2\}$ is a stable coalition for $n=6$, and is profitable for the retailer. In

\footnotetext{
13 In a model of sequential bilateral bargaining, Xiao (2018) orders players according to their valuations of striking a bargain, and derives conditions on neighbouring values that secure the existence of an equilibrium in his model.

14 Note that $n=6, k=3$ lies to the right of the whole line so that owner 3 does not join the bargaining group.
} 
contrast $B=\{1,2,3\}$ is still profitable for the retailer, but no longer stable for $n=7$. When the bargaining power of the owners increases, indicated by a rise in $m_{1}$ and/or $\delta$, less bargaining groups are profitable for the retailer to try to implement, but more bargaining groups are stable.

The retailer may then be able to use the order of negotiations in order to move away from the status quo solution, $I$. However, even in the case in which a great deal of structure is placed on the group formation problem, the stable groups that arise may not be profitable for the retailer to implement.

\section{Conclusion}

We have considered a simple vertical industry in which a retailer combines complementary components to make a final product. Initially, all component owners set their intermediate price to maximize own profit, and our focus has been on whether group bargaining has the potential to increase industry and retailer profit above the status quo level. By allowing the bargaining group to negotiate its component prices first, the retailer can encourage the endogenous formation of a stable bargaining group in which no component owner wants to leave, and no outside component owner finds it profitable to enter. Furthermore, the retailer can use this framework to increase his own profit. When there are four or more component holders, the retailer cannot implement his first-best, fully cooperative solution in which all owners join the bargaining group. However, we present conditions under which a stable bargaining group consisting of some owners will arise, and when this increases the profit of the retailer.

Our results build upon several simplifying assumptions that can be relaxed in future work. First, we have assumed that each component is essential in the production of the final good. Differentiated bargaining powers can capture the fact that some components might be more valuable than others (in the sense of having a better outside option). Hence, in the production of the final good, a more general formulation would allow for the fact that some inputs are essential whilst others are not. Heinzel and Hoof (2020) considered various degrees of input differentiation. Second, the bargaining framework that we have assumed is stylized in the sense that all of those belonging to the bargaining group negotiate with the retailer at the same time, maximizing the Nash product. An alternative would be to consider each member of the bargaining group negotiating bilaterally with the retailer, without knowing the result of other deals (Nash-in-Nash bargaining as discussed by Collard-Wexler et al. 2019). Third, we have assumed the endogenous formation of a single bargaining group, but in practice several alliances may form in the supply chain. Given this, there is also scope for investigating the order of negotiations between different bargaining groups, and how this affects market profits. A similar situation was considered in Clark and Pereau (2009) in which bargaining was assumed to happen in an alternating offers framework.

Funding Open Access funding provided by UiT The Arctic University of Norway (incl University Hospital of North Norway). 
Open Access This article is licensed under a Creative Commons Attribution 4.0 International License, which permits use, sharing, adaptation, distribution and reproduction in any medium or format, as long as you give appropriate credit to the original author(s) and the source, provide a link to the Creative Commons licence, and indicate if changes were made. The images or other third party material in this article are included in the article's Creative Commons licence, unless indicated otherwise in a credit line to the material. If material is not included in the article's Creative Commons licence and your intended use is not permitted by statutory regulation or exceeds the permitted use, you will need to obtain permission directly from the copyright holder. To view a copy of this licence, visit http://creativecommons.org/licenses/by/4.0/.

\section{Appendix}

\section{Lemma 1}

Proof The first-order condition for owner $i^{\prime} s$ maximization is

$$
\frac{\partial \pi_{i}}{\partial w_{i}}=1-\sum_{j=1}^{n} w_{j}-w_{i}=0
$$

The unique solution to this system is $w_{i}=w^{I}=\frac{1}{1+n}$. The second-order condition for a maximum is fulfilled since $\frac{\partial^{2} \pi_{i}}{\partial w_{i}^{2}}=-2<0$. Profits and product price are recovered by substitution.

\section{Lemma 2}

Proof Maximizing the program with respect to $w_{i}$ yields the following first-order conditions:

$$
\frac{\partial \Omega}{\partial w_{i}}=\Omega\left(\frac{m_{i}}{w_{i}}-\frac{(2 r+M)}{1-W}\right)=0, i=1, \ldots, n .
$$

Clearly, a maximum will not involve $\Omega=0$, ruling out solutions in which each $w_{i}=0$, or $W=1$. The bracketed expression is then zero, giving

$$
w_{i}=\frac{m_{i}(1-W)}{2 r+M}
$$

which can be summed for all owners to reveal the sum of the component prices as

$$
W=\frac{M}{2(r+M)} .
$$


Inserting (34) into (33) reveals the expression for each component price as $w_{i}^{C}$ as stated. The Hessian associated with the Nash program is

$$
H=\left(\begin{array}{ccccc}
\frac{\partial^{2} \Omega}{\partial w_{1}^{2}} & \frac{\partial^{2} \Omega}{\partial w_{2} \partial w_{1}} & \cdot & \cdot & \frac{\partial^{2} \Omega}{\partial w_{n} \partial w_{1}} \\
\frac{\partial^{2} \Omega}{\partial w_{1} \partial w_{2}} & \frac{\partial^{2} \Omega}{\partial w_{2}^{2}} & \cdot & \cdot & \cdot \\
\cdot & \cdot & \frac{\partial^{2} \Omega}{\partial w_{3}^{2}} & \cdot & \cdot \\
\frac{\partial^{2} \Omega}{\partial w_{1} \partial w_{n}} & \frac{\partial^{2} \Omega}{\partial w_{2} \partial w_{n}} & \cdot & \cdot & \cdot \\
\frac{\partial^{2} \Omega}{\partial w_{n}^{2}}
\end{array}\right)
$$

where

$$
\begin{aligned}
\frac{\partial^{2} \Omega}{\partial w_{i}^{2}} & =\frac{-4(r+M)^{2}}{2 r+M} \Omega\left(1+\frac{2 r+M}{m_{i}}\right) \\
\frac{\partial^{2} \Omega}{\partial w_{k} \partial w_{i}} & =\frac{-4(r+M)^{2}}{2 r+M} \Omega
\end{aligned}
$$

when evaluated at $w_{i}^{C}$. Hence, around the equilibrium,

$$
H=\frac{4(r+M)^{2}}{2 r+M} \Omega\left(\begin{array}{ccccc}
-\left(1+\frac{2 r+M}{m_{1}}\right) & -1 & -1 & \cdot & -1 \\
-1 & -\left(1+\frac{2 r+M}{m_{2}}\right) & \cdot & . & \cdot \\
-1 & \cdot & -\left(1+\frac{2 r+M}{m_{3}}\right) & \cdot & \cdot \\
\cdot & \cdot & \cdot & \cdot & -1 \\
-1 & -1 & -1 & . & -\left(1+\frac{2 r+M}{m_{n}}\right)
\end{array}\right) \text {. }
$$

The determinant of the $k^{\prime} t h$ principal minor $(k=1, \ldots, n)$ is

$$
D_{k}=\frac{(-1)^{k}(2 r+M)^{k-1}}{\prod_{j=1}^{k} m_{j}}\left(2 r+M+\sum_{j=1}^{k} m_{j}\right)
$$

which is positive (negative) for even (odd) $k$ so that the Hessian is negative definite at the equilibrium, implying that the solution characterizes a local maximum.

Expressions for price and profit are recovered by substitution.

\section{Proposition 1}

Proof The first comparisons are straightforward. For component owner $i$, we have

$$
\begin{aligned}
& \pi_{i}^{I}-\pi_{i}^{C}(r, \mathbf{m})=\frac{1}{2(1+n)^{2}}-\frac{1}{8} \frac{m_{i}\left(2 r+M_{-i}+m_{i}\right)}{\left(r+M_{-i}+m_{i}\right)^{2}} \\
& =\frac{1}{8} \frac{-(n+3)(n-1) m_{i}^{2}+\left(\left(7-2 n-n^{2}\right) M_{-i}-2 r(n+3)(n-1)\right) m_{i}+4\left(M_{-i}+r\right)^{2}}{\left(r+M_{-i}+m_{i}\right)^{2}(n+1)^{2}}>0 .
\end{aligned}
$$


The numerator of this expression is a strictly concave function of $m_{i}$, with negative slope and positive value at $m_{i}=0$. It follows that the numerator has one positive root, $m_{i}^{+}\left(n, r, M_{-i}\right)$, and that $\pi_{i}^{I}>\pi_{i}^{C}(r, \mathbf{m})$ for $m_{i}^{+}\left(n, r, M_{-i}\right)>m_{i}$. Direct calculation gives

$$
\begin{aligned}
& m_{i}^{+}\left(n, r, M_{-i}\right)=\frac{\left(7-2 n-n^{2}\right) M_{-i}}{2(n+3)(n-1)}-r \\
& +\frac{(1+n) \sqrt{(n+1)^{2} M_{-i}^{2}+4 r(n+3)(n-1) M_{-i}+4 r^{2}(n+3)(n-1)}}{2(n+3)(n-1)}
\end{aligned}
$$

\section{Lemma 3}

Proof (i) Case $N B$. Let the intermediate prices set in the first round by $j \in N$ be given by $w_{j}$, and consider the decisions of actors $i \in B$; furthermore, let $\omega_{N}=\sum w_{j}$ for $j \in N$, and $\omega_{B}=\sum w_{i}$ for $i \in B$. The Nash product can then be written as

$$
\Omega^{N B}=\left(\frac{1}{2}\right)^{2 r+\mu}\left(1-\omega_{B}-\omega_{N}\right)^{2 r+\mu} \prod_{i \in B}\left(w_{i}\right)^{m_{i}}
$$

Maximizing (35) with respect to $w_{k}$ for $k \in B$ gives the first-order condition as:

$$
\frac{\partial \Omega^{N B}}{\partial w_{k}}=\Omega^{N B}\left(\frac{m_{k}}{w_{k}}-\frac{(2 r+\mu)}{\left(1-\omega_{B}-\omega_{N}\right)}\right)=0
$$

with solution

$$
w_{k}=\frac{m_{k}\left(1-\omega_{B}-\omega_{N}\right)}{2 r+\mu}
$$

Summing (36) across all members of $B$ yields

$$
\omega_{B}=\frac{\mu\left(1-\omega_{B}-\omega_{N}\right)}{2 r+\mu}
$$

which implies that the sum of all component prices for group $B$ is

$$
\omega_{B}=\frac{\mu\left(1-\omega_{N}\right)}{2(r+\mu)} .
$$

Inserting (37) into (36) gives the component price for each bargaining patent owner as a function of the (sum of) the prices set at the first stage:

$$
w_{k}=\frac{m_{k}\left(1-\omega_{N}\right)}{2(r+\mu)}, k \in B
$$

The second-order conditions for the maximization of the Nash program are fulfilled; showing this is analagous to the proof of Lemma 2, and is omitted here. 
Consider now the decisions made at the first stage by the component owners $j \in N$ to maximize

$$
\pi_{j}=\frac{1}{2} w_{j}\left(1-\omega_{B}-\omega_{N}\right)
$$

where one must recall that the choice variable appears indirectly in $\omega_{B}$ through (38), and directly in $\omega_{N}$. The first-order condition for a maximum is

$$
\frac{\partial \pi_{j}}{\partial w_{j}}=\left(1-\omega_{B}-\omega_{N}\right)+w_{j}\left(\frac{\mu}{2(r+\mu)}-1\right)=0 .
$$

This system has a unique solution, and this is symmetric:

$$
w_{j}^{N B}=\frac{1}{1+n-\beta}, j \in N .
$$

The second order condition for $j^{\prime} s$ maximization is fulfilled since $\frac{\partial^{2} \pi_{j}}{\partial w_{j}^{2}}=-\frac{2 r+\mu}{r+\mu}<0$.

Using (39) in (38) gives the final reduced expression for the component prices set by the members of $B$ :

$$
w_{k}^{N B}=\frac{m_{k}}{2(r+\mu)(1+n-\beta)}, k \in B
$$

Inserting (39) and (40) into (4) gives the product price as

$$
p^{N B}=\frac{2(r+\mu)(1+2(n-\beta))+\mu}{4(r+\mu)(1+n-\beta)}
$$

Given the product price set by the retailer, the profits of the component owners and retailer are given by (5) and (6). Using (39) and (40) reveals the final profits of the actors as given in Lemma 3 by equations (22) and (18). In the calculation of $\pi^{N B}$, the profit of the group that bargains is given by $\frac{1}{8} \frac{\mu(2 r+\mu)}{(r+\mu)^{2}(1+n-\beta)^{2}}$, and for group $N$ by $(n-\beta) \frac{1}{4} \frac{2 r+\mu}{(r+\mu)(1+n-\beta)^{2}}$; these are added to the profit of the retailer to get the final expression (26).

(ii) Case $B N$ is proved in a similar manner, yielding

$$
\begin{aligned}
w_{k}^{B N} & =\frac{m_{k}}{2(r+\mu)}, k \in B \\
w_{j}^{B N} & =\frac{2 r+\mu}{2(r+\mu)(1+n-\beta)}, j \in N \\
p^{B N} & =\frac{2(r+\mu)(1+2(n-\beta))+\mu}{4(r+\mu)(1+n-\beta)}
\end{aligned}
$$

and the payoffs (20), (22) and (26). 
(iii) Case $S I M$ gives

$$
\begin{aligned}
w_{k}^{S I M} & =\frac{m_{k}}{2(r+\mu)+(n-\beta)(\mu+2 r)}, k \in B \\
w_{j}^{S I M} & =\frac{2 r+\mu}{2(r+\mu)+(n-\beta)(\mu+2 r)}, j \in N \\
p^{S I M} & =\frac{2((r+\mu)+(n-\beta)(\mu+2 r))+\mu}{2(2(r+\mu)+(n-\beta)(\mu+2 r))}
\end{aligned}
$$

and the payoffs (23)-(25) and (27).

Proposition 2

Proof The profit comparisons are mostly straightforward. For the component owners who are outside of the bargaining group, notice that

$$
\pi_{j}^{N B}>\pi_{j}^{S I M} \Leftrightarrow \sqrt{\frac{2(r+\mu)}{2 r+\mu}}>n-\beta, \text { for } j \in N
$$

where one can easily determine that $\sqrt{\frac{2(r+\mu)}{2 r+\mu}} \in[1, \sqrt{2}]$. Hence, if group $N$ is a single component owner $(n-\beta=1)$, then it prefers $N B$ to $S I M$; when there are at least two members in $N$, then they would prefer the framework in which the two groups set component prices simultaneously.

For the comparison of $\pi_{R}^{C}$ and $\pi_{R}^{S I M}$, note that

$$
\pi_{R}^{C}(r, \mathbf{m})-\pi_{R}^{S I M}=\frac{\chi v}{16(M+r)^{2} 2(r+\mu)+(n-\beta)(2 r+\mu)^{2}}
$$

with

$$
\begin{aligned}
& \chi=(\mu(n-\beta)+2 r(n-\beta-1)) M+2 r(\mu(n-\beta+1)+2 r(n-\beta))>0 \\
& v=(\mu(n-\beta+4)+2 r(n-\beta+3)) M+2 r(\mu(n-\beta+3)+2 r(n-\beta+2))>0
\end{aligned}
$$

since $n-\beta$ is at least 1 under the conditions of the Proposition.

Proposition 3

\section{Proof Part (i)}

1. In the status quo, all component owners set price independently, each earning (9). Suppose that owner $j$ moves to group $B$, leaving $n-1$ in group $N$. This gives a profit increase to $j$ which using (18) and (19) when $\mu$ and $\beta$ are zero is

$$
\frac{m_{j}\left(2+m_{j}\right)}{8\left(1+m_{j}\right)^{2} n^{2}}-\frac{1}{2(1+n)^{2}}=\frac{-\left((3 n+1)(n-1) m_{j}^{2}+2(3 n+1)(n-1) m_{j}+4 n^{2}\right)}{8 n^{2}\left(1+m_{j}\right)^{2}(n+1)^{2}}
$$


which is obviously negative since $n \geq 2$. Hence no component owner would want to be the only firm to bargain alone, and the solution with all $n$ owners in $N$ is internally stable.

2. Suppose that a group of $\beta$ component owners are in group $B$, with $n-\beta$ in group $N$. Let $\mu_{-i}$ be sum of all bargaining powers in $B$ except owner $i$. From (19) and (18), $i$ wants to stay in $B$ if his payoff by belonging to group B of size $\beta$ exceeds his payoff when he moves to group $N$ of size $n-\beta+1$

$$
\frac{1}{8} \frac{m_{i}\left(2+\mu_{-i}+m_{i}\right)}{\left(1+\mu_{-i}+m_{i}\right)^{2}(1+n-\beta)^{2}}-\frac{1}{4} \frac{2+\mu_{-i}}{\left(1+\mu_{-i}\right)(2+n-\beta)^{2}}>0
$$

which can be shown to hold for

$$
0>\Gamma\left(m_{i}, \mu_{-i}, n, \beta\right)
$$

where

$$
\begin{aligned}
\Gamma\left(m_{i}, \mu_{-i}, n, \beta\right)= & \left((3(n-\beta)+4)(n-\beta)+\left((n-\beta)^{2}-2\right) \mu_{-i}\right) m_{i}^{2} \\
& +(n-\beta)\left(2+\mu_{-i}\right)\left(1+\mu_{-i}\right)(3(n-\beta)+4) m_{i} \\
& +2\left(2+\mu_{-i}\right)\left(1+\mu_{-i}\right)^{2}(n-\beta+1)^{2}
\end{aligned}
$$

Suppose first that $n-\beta \geq 2$, which makes $\Gamma\left(m_{i}, \mu_{-i}, n, \beta\right)$ a convex function of $m_{i}$ with a positive slope and positive value at $m_{i}=0$. Hence, $\Gamma\left(m_{i}, \mu_{-i}, n, \beta\right)>0$, and $i$ wants to leave the bargaining group, rendering it unstable.

Suppose that $n-\beta=1$. If $7>\mu_{-i}$, then $\Gamma\left(m_{i}, \mu_{-i}, n-\beta=1\right)$ is still a convex function, and the previous analysis holds. If $7<\mu_{-i}$, then $\Gamma\left(m_{i}, \mu_{-i}, n-\beta=1\right)$ is concave in $m_{i}$, and $0>\Gamma\left(m_{i}, \mu_{-i}, n-\beta=1\right)$ holds for

$$
m_{i}>\frac{1}{2}\left(1+\mu_{-i}\right) \frac{14+7 \mu_{-i}+3 \sqrt{\left(9 \mu_{-i}-14\right)\left(2+\mu_{-i}\right)}}{\mu_{-i}-7}
$$

Note that the threshold that $m_{i}$ must exceed in order for $i$ to stay in the bargaining group is larger than $\mu_{-i}$ since

$$
\begin{aligned}
& \frac{1}{2}\left(1+\mu_{-i}\right) \frac{14+7 \mu_{-i}+3 \sqrt{\left(9 \mu_{-i}-14\right)\left(2+\mu_{-i}\right)}}{\mu_{-i}-7}-\mu_{-i} \\
& =\frac{1}{2} \frac{35 \mu_{-i}+14+5 \mu_{-i}^{2}+3\left(\mu_{-i}+1\right) \sqrt{\left(9 \mu_{-i}-14\right)\left(2+\mu_{-i}\right)}}{\mu_{-i}-7}>0 .
\end{aligned}
$$

Suppose that component owner $i$ has the lowest bargaining power in group $B$. In order to remain in the group it must have a power which exceeds a threshold value, which in turn is larger than the sum of all other bargaining powers in the group. Since $i$ has the lowest bargaining power, this cannot hold, and firm $i$ wishes to leave the bargaining group, making it unstable. 
Suppose finally that $\beta=n$, so that the bargaining group is now the grand coalition of all component owners. Owner $i$ stays in the coalition if $0>\Gamma\left(m_{i}, \mu_{-i}, n=\beta\right)$, which holds for $m_{i}>\frac{1}{\mu_{-i}}\left(1+\mu_{-i}\right) \sqrt{\mu_{-i}\left(2+\mu_{-i}\right)}>\mu_{-i}$, a contradiction for the component holder with the lowest bargaining power in the group. This owner will always want to leave the grand coalition, rendering it unstable.

Hence $B=\{\varnothing\}$ is the uniquely stable coalition and solution $I$, with all owners setting price independently, ensues.

Part (ii)

1. Suppose all are in $N$ (i.e. $\beta=0$ ), component owner $i$ has no incentive to break out and bargain as a singleton-using (23) - if:

$$
\begin{aligned}
& \frac{1}{2(n+1)^{2}}-\frac{1}{2} m_{i} \frac{2+m_{i}}{\left(2\left(1+m_{i}\right)+(n-1)\left(2+m_{i}\right)\right)^{2}} \\
& =\frac{2 n^{2}+\left(n^{2}-1\right) m_{i}}{(n+1)^{2}\left(m_{i}+2 n+n m_{i}\right)^{2}}>0
\end{aligned}
$$

which is true. Hence the coalition with all component owners in $N$ is internally stable (and trivially externally stable).

2. Suppose that there is a coalition of $\beta \in[1, n-1]$ component owners in $B$, with the remainder in $N$. Using (23) and (24), consider owner $i$ who has the lowest bargaining power in the group. It will stay in this coalition as long as

$$
\begin{aligned}
& \frac{m_{i}\left(2+\mu_{-i}+m_{i}\right)}{\left(2\left(1+\mu_{-i}+m_{i}\right)+(n-\beta)\left(2+\mu_{-i}+m_{i}\right)\right)^{2}} \\
& -\frac{\left(2+\mu_{-i}\right)^{2}}{\left(2\left(1+\mu_{-i}\right)+(n-\beta+1)\left(2+\mu_{-i}\right)\right)^{2}}>0
\end{aligned}
$$

where $\mu_{-i}$ is the sum of all bargaining powers except for $i$. This condition can be reduced to the following expression

$$
\Phi\left(m_{i}, \mu_{-i}, n, \beta\right)>0
$$

where

$$
\begin{aligned}
& \Phi\left(m_{i}, \mu_{-i}, n, \beta\right) \\
& =\mu_{-i}\left(2\left(2+\mu_{-i}\right)(n-\beta)+5 \mu_{-i}+8\right) m_{i}^{2} \\
& \quad-\left(\mu_{-i}+2\right)\left(4(n-\beta)\left(\mu_{-i}+1\right)(n-\beta+2)\right. \\
& \left.\quad+\mu_{-i}^{2}\left(2(n-\beta)+(n-\beta)^{2}-1\right)\right) m_{i} \\
& \quad-\left(\mu_{-i}+2\right)^{2}\left(\left(2+\mu_{-i}\right)(n-\beta)+2\left(\mu_{-i}+1\right)\right)^{2}
\end{aligned}
$$

which is quadratic and convex in $m_{i}$, with negative slope and value at $m_{i}=0$. Hence the equation $\Phi\left(m_{i}, \mu_{-i}, n, \beta\right)=0$ has one positive root $\bar{m}\left(\mu_{-i}, n, \beta\right)$, and the value of $m_{i}$ must be above this for $\Phi\left(m_{i}, \mu_{-i}, n, \beta\right)>0$. It can be 
shown that that $\bar{m}\left(\mu_{-i}, n, \beta\right)$ is strictly increasing in $n-\beta$ (the number of members in $N$ ), and at the minimum value of $\bar{m}\left(\mu_{-i}, n, \beta\right)$ (which occurs for $n-\beta=1)$ we have $\bar{m}\left(\mu_{-i}, n-\beta=1\right)>\mu_{-i} .{ }^{15}$

Since we have defined $m_{i}$ to be the lowest bargaining power in the group it is impossible that this is larger than the sum of the bargaining powers of all other members, and hence component owner $i$ wants to leave the bargaining group rendering it unstable.

3. Suppose finally that all component owners belong to the bargaining group $(\beta=n)$. The analysis from part (ii) 2 above is still valid here, and the component owner (by definition owner $n$ ) with the lowest bargaining power will want to stay in the grand coalition as long as

$m_{n}>\bar{m}\left(\mu_{-n}, \beta=n\right)=\frac{\left(\mu_{-n}+2\right)\left(\left(3 \mu_{-n}+4\right) \sqrt{\mu_{-n}\left(9 \mu_{-n}+8\right)}-\mu_{-n}^{2}\right)}{\left(2 \mu_{-n}\right)\left(5 \mu_{-n}+8\right)}$

Consider the value of $\bar{m}\left(\mu_{-n}, \beta=n\right)$ in relation to the average bargaining power of all component owners except $n, \frac{\mu_{-n}}{n-1}$ :

$$
\bar{m}\left(\mu_{-n}, \beta=n\right)-\frac{\mu_{-n}}{n-1}
$$

which can be shown to be positive for

$$
n>\frac{\left(\mu_{-n}+2\right)\left(3 \mu_{-n}+4\right) \sqrt{\left(8+9 \mu_{-n}\right) \mu_{-n}}+\left(14+9 \mu_{-n}\right) \mu_{-n}^{2}}{\left(\mu_{-n}+2\right)\left(\left(4+3 \mu_{-n}\right) \sqrt{\left(8+9 \mu_{-n}\right) \mu_{-n}}-\mu_{-n}^{2}\right)} .
$$

The right hand side of this expression is an increasing, concave function in $\mu_{-n}$ that takes values in the range $(1,2.25)$. Hence for $n \geq 3$, component owner $n$ will not leave the grand coalition as long as $m_{n}>\bar{m}\left(\mu_{-n}, \beta=n\right)$, but since $\bar{m}\left(\mu_{-n}, \beta=n\right)-\frac{\mu_{-n}}{n-1}$, this implies $m_{n}>\frac{\mu_{-n}}{n-1}$. The bargaining power of the weakest component owner must be larger than the average of all the other component owners' bargaining power, a contradiction. Hence there is no stable grand coalition for $n \geq 3$. Combining (ii) 1., 2., and 3. proves that $B=\{\varnothing\}$ for $n \geq 3$, and all owners set intermediate prices independently, giving solution $I$.

4. When $n=2$, we can calculate directly from (23) and (24) that firm 2 with the lowest bargaining power will stay in the grand coalition as long as

$$
\frac{1}{2} m_{2} \frac{2+m_{1}+m_{2}}{\left(2\left(1+m_{1}+m_{2}\right)\right)^{2}}-\frac{1}{2} \frac{\left(2+m_{1}\right)^{2}}{\left(2\left(1+m_{1}\right)+\left(2+m_{1}\right)\right)^{2}}>0
$$

$\overline{15 \text { We can show that } \bar{m}\left(\mu_{-i}, n, \beta\right)}$

$$
=\frac{\left(\mu_{-i}+2\right)}{2} \frac{(n-\beta)\left(\mu_{-i}+2\right)^{2}((n-\beta)+2)-\mu_{-i}^{2}+\left(3 \mu_{-i}+4+2(n-\beta)+(n-\beta) \mu_{-i}\right) \sqrt{\zeta}}{\mu_{-i}\left(4(n-\beta)+5 \mu_{-i}+2(n-\beta) \mu_{-i}+8\right)}
$$

with $\zeta=(n-\beta)\left(\mu_{-i}+2\right)\left(2(n-\beta)+6 \mu_{-i}+(n-\beta) \mu_{-i}\right)+\mu_{-i}\left(9 \mu_{-i}+8\right)$. 
which requires $m_{2}>\bar{m}\left(m_{1}, \beta=n=2\right)=\frac{\left(m_{1}+2\right)\left(\left(3 m_{1}+4\right) \sqrt{m_{1}\left(9 m_{1}+8\right)}-m_{1}^{2}\right)}{2 m_{1}\left(5 m_{1}+8\right)}$. Owner 2 wants to stay in the coalition for $m_{1}>m_{2}>\bar{m}\left(m_{1}, \beta=n=2\right)$. It is straightforward to verify that also 1 remains in the coalition for these combinations of bargaining powers. Hence for these values of $m_{1}, m_{2}, B=$ $\{1,2\}$ is a stable coalition, and solution $C$ can be achieved. Part (ii) 1 of the proof shows that $B=\{\varnothing\}$ is also stable, and that a singleton in the bargaining set is not.

\section{Proposition 4}

Proof If all $n$ component owners belong to $N$, then using (20) and (9) the increase in profit to $i$ from bargaining alone is

$$
\frac{1}{8} m_{i} \frac{2+m_{i}}{\left(1+m_{i}\right)^{2} n}-\frac{1}{2(1+n)^{2}}=\frac{1}{8}\left(2 n+(n-1) m_{i}\right) \frac{(n-1) m_{i}-2}{n\left(1+m_{i}\right)^{2}(n+1)^{2}}
$$

which is positive for $m_{i}>\frac{2}{n-1}$. If this holds for $m_{1}$ which is the highest bargaining power, then the owner will have an incentive to leave $N$, making it unstable.

\section{Proposition 5}

Proof Suppose that all component owners are in the bargaining group. Let the sum of all owners' bargaining power except actor $n$ be given by $\mu_{-n}$. The component owner with the lowest bargaining power, $m_{n}$, has no incentive to leave the group unilaterally_using (20) and (21) — if

$$
\frac{1}{8} m_{n} \frac{2+\mu_{-n}+m_{n}}{\left(1+\mu_{-n}+m_{n}\right)^{2}}-\frac{1}{8} \frac{\left(2+\mu_{-n}\right)^{2}}{4\left(1+\mu_{-n}\right)^{2}}>0 .
$$

This holds if $\digamma\left(\mu_{-n}, m_{n}\right)>0$, where

$$
\digamma\left(\mu_{-n}, m_{n}\right)=\mu_{-n}\left(3 \mu_{-n}+4\right) m_{n}^{2}+2 \mu_{-n}\left(\mu_{-n}+2\right)\left(\mu_{-n}+1\right) m_{n}-\left(\mu_{-n}+2\right)^{2}\left(\mu_{-n}+1\right)^{2} .
$$

$\digamma\left(\mu_{-n}, m_{n}\right)$ is convex in $m_{n}$, with a positive slope and negative value at $m_{n}=0$. Hence, $\digamma\left(\mu_{-n}, m_{n}\right)>0$ and component owner $n$ will stay in the bargaining group if $m_{n}$ is larger than the positive root of $\digamma\left(\mu_{-n}, m_{n}\right)=0$, given by

$$
\tilde{m}_{n}\left(\mu_{-n}\right)=\frac{\left(\mu_{-n}+2\right)}{\mu_{-n}\left(3 \mu_{-n}+4\right)}\left(2 \sqrt{\mu_{-n}\left(\mu_{-n}+1\right)^{3}}-\mu_{-n}\left(1+\mu_{-n}\right)\right) .
$$

Consider the relation between $\tilde{m}_{n}\left(\mu_{-n}\right)$ and the average bargaining power of all in the bargaining group except $n, \frac{\mu_{-n}}{n-1}$ which-by definition-must be larger than $m_{n}$. If $\widetilde{m}_{n}\left(\mu_{-n}\right)>\frac{\mu_{-n}}{n-1}$, then component owner $n$ will leave the bargaining group since staying in would require $m_{n}>\tilde{m}_{n}\left(\mu_{-n}\right)>\frac{\mu_{-n}}{n-1}$, a contradiction. It can be verified 
that $\tilde{m}_{n}\left(\mu_{-n}\right)>\frac{\mu_{-n}}{n-1}$ if

$$
n>\frac{\left(2\left(\mu_{-n}+2\right) \sqrt{\mu_{-n}\left(\mu_{-n}+1\right)^{3}}+\mu_{-n}\left(\mu_{-n}+2 \mu_{-n}^{2}-2\right)\right)}{\left(2\left(\mu_{-n}+2\right) \sqrt{\mu_{-n}\left(\mu_{-n}+1\right)^{3}}-\mu_{-n}\left(\mu_{-n}+2\right)\left(\mu_{-n}+1\right)\right)} .
$$

The right hand side is concave and increasing in $\mu_{-n}$, converging to 4 from below as $\mu_{-n}$ gets large. Hence $\tilde{m}_{n}\left(\mu_{-n}\right)>\frac{\mu_{-n}}{n-1}$ for $n \geq 4$, and firm $n$ would withdraw from the grand coalition.

Roots of $\Delta=0$ in case $B N$

Consider $\Delta$ in (32); it is more convenient to exclude a parameter in deriving Fig. 2 by writing $x=n-k$ which is the number of owners outside of the bargaining group if $k$ enters. The positive root of $\Delta=0$ can be determined straightforwardly as

$$
\begin{gathered}
\frac{-\left(\left(\mu_{-k}+2\right)\left(\mu_{-k}+1\right)\left(\left(\mu_{-k}+1\right) x^{2}+2 \mu_{-k}(x+1)\right)\right)+\lambda}{2\left(\left(\mu_{-k}+1\right)^{2} x^{2}+\mu_{-k}\left(3 \mu_{-k}+4\right)(x+1)\right)}, \text { where } \\
\lambda=\sqrt{\begin{array}{c}
\left(\left(\left(\mu_{-k}+2\right)\left(\mu_{-k}+1\right)\left(\left(\mu_{-k}+1\right) x^{2}+2 \mu_{-k}(x+1)\right)\right)\right)^{2} \\
+4\left(\left(\mu_{-k}+1\right)^{2} x^{2}+\mu_{-k}\left(3 \mu_{-k}+4\right)(x+1)\right)\left(\mu_{-k}+2\right)^{2}\left(\mu_{-k}+1\right)^{2}(x+1)
\end{array}} .
\end{gathered}
$$

\section{References}

Belleflamme P (2000) Stable coalition structures with open membership and asymmetric firms. Games Econ Behav 30:1-21

Bergh HN, Gramstad AR, Skaar J (2020) Unilateral price effects and vertical relations between merging and non-merging firms. Rev Ind Organ 57:131-143

Bloch F (2002) Coalitions and networks in industrial organization. Manch Sch 70(1):36-55

Brenner S (2009) Optimal formation rules for patent pools. Econ Theor 40:373-388

Choi SC (1991) Price competition in a channel structure with a common retailer. Mark Sci 10(4):271-296

Clark DJ, Pereau J-C (2009) Fragmented property rights and royalty bargaining. J Econ Behav Org 72(1):546-553

Collard-Wexler A, Gowrisankaran G, Lee RS (2019) Nash-in-Nash bargaining: a microfoundation for applied work. J Polit Econ 127(1):163-195

D’Aspremont C, Jacquemin A, Jaskold Gabszewicz J, Weymark JA (1983) On the stability of collusive price leadership. Can J Econ 16(1):17-25

Dobson PW, Waterson M (1997) Countervailing power and consumer prices. Econ J 107:418-430

Draganska M, Klapper D, Villas-Boas SB (2010) A larger slice or a larger pie? An empirical investigation of bargaining power in the distribution channel. Mark Sci 29(1):57-74

Elfenbein HA, Curhan JR, Eisenkraft N, Shirako A, Baccaro L (2008) Are some negotiators better than others? Individual differences in bargaining outcomes. J Res Pers 42:1463-1475

Flores-Fillol R, Moner-Colonques R (2011) Endogenous mergers of complements with mixed bundling. Rev Ind Organ 39:231-251

Gaudin G (2018) Vertical bargaining and retail competition: what drives countervailing power? Econ J 128:2380-2413 
Heinzel J, Hoof S (2020) Oligopolistic upstream competition with differentiated inputs, center for international economics, WP Series $n^{\circ} 1$

Horn H, Wolinsky A (1988) Bilateral monopolies and incentives for merger. Rand J Econ 19(3):408-419

Iozzi A, Valletti T (2014) Vertical bargaining and countervailing power. Am Econ J Microecon 6(3):106-135

Krasteva S, Yildirim H (2012) Payoff uncertainty, bargaining power, and the strategic sequencing of bilateral negotiations. Rand J Econ 43(3):514-536

Krasteva S, Yildirim H (2019) Strategic ignorance in sequential procurement. Am Econ J Microecon 11(2):131-172

Laussel D (2008) Buying back subcontractors: the strategic limits of backward integration. J Econ Manag Strategy 17(4):895-911

Lax D, Sebenius J (1992) The manager as negotiator: the negotiator's dilemma: creating and claiming value. In: Goldberg Stephen, Sander Frank, Rogers Nancy (eds) Dispute resolution, 2nd edn. Little Brown and Co., Boston, pp 49-62

Leider S, Lovejoy WS (2016) Bargaining in supply chains. Manag Sci 62(10):3039-3058

Leveque F, Meniere Y (2011) Patent pool formation: timing matters. Inf Econ Policy 23:243-251

Möller M (2007) The timing of contracting with externalities. J Econ Theory 133(1):484-503

Münster J, Reisinger M (2018) sequencing bilateral negotiations with externalities. Working paper, April. https://www.carloalberto.org/wp-content/uploads/2019/02/Muenster-Reisinger-April16-2018-1.pdf

Muthoo A (1996) A bargaining model based on the commitment tactic. J Econ Theory 69:134-152

Nagarajan M, Bassok Y (2008) A bargaining framework in supply chains: the assembly problem. Manag Sci 54:1482-1496

Reisinger M, Tarantino E (2019) Patent pools, vertical integration and downstream competition. Rand J Econ 50(1): 168-200

Rubinstein A (1982) Perfect equilibrium in a bargaining model. Econometrica 50:97-109

Sheu J-B, Gao X-Q (2014) Alliance or no alliance-bargaining power in competing reverse supply chains. Eur J Oper Res 233:313-325

Spulber DF (2016) Patent licensing and bargaining with innovative complements and substitutes. Res Econ 70:693-713

Spulber DF (2017) Complementary monopolies and bargaining. J Law Econ 60:29-74

Stigler JG (1950) Monopoly and oligopoly by merger. Am Econ Rev 40:23-34

von Ungern-Sternberg T (1996) Countervailing power revisited. Int J Ind Organ 14:507-520

Winkler K (2006) Negotiations with asymmetrical distribution of power: conclusions from dispute resolution in network industries. Physica-Verlag, Heidelberg

Xiao J (2018) Bargaining orders in a multi-person bargaining game. Games Econ Behav 107:364-379

Yi S-S (1997) Stable coalition structures with externalities. Games Econ Behav 20(2):201-237

Publisher's Note Springer Nature remains neutral with regard to jurisdictional claims in published maps and institutional affiliations. 